\title{
A NOTE ON THE GROSS ESTIMATE OF FOREST INSECT DAMAGE IN CANADA ${ }^{1}$
}

\author{
By A. W. A. Brown, \\ In Charge, Forest Insect Survey, Division of Entomology, Ottawa
}

N RECENT years, workers in forest entomology have become increasingly cautious in advancing any quantitative estimates on the amount of damage caused by insects. As a result, we have had nothing concrete to give us a picture of the relative importance of present destructive forest insect outbreaks.

The main reasons advanced for not attempting to give any figure are:

1. The virtual impossibility of obtaining such a figure in cases where very extensive areas are involved.

2. The inaccuracy of the figure, if obtained.

3. The inadequacy of a mere figure for damage, whether in cords or in dollars, to evaluate its relative importance in other respects; if in cords, with regard to accessibility and merchantability; and whether in cords or dollars, with regard to fire hazard, site deterioration, ecological succession, amenity value and the like.

In this paper, an attempt will be made to answer the three points enumerated above:

1. Figures dealing with insect damage even over extensive areas are not impossible of attainment. It is not necessary, as seems to be the impression in some circles, to make a detailed cruise acre by acre. Application of the sampling method, combined with a sense of proportion and an idea of the probable error, will tell us what we want to know.

2. The claim of the inaccuracy of such a figure may be countered by the simple question: What is understood by the usual terms "heavy," "moderate" and "light" to describe the degree of infestation? These are mere terms of quality, and any quantitative figure, within a reasonable limit of error, is more definite and, therefore, generally more satisfactory.

3. The inadequacy of a figure to take care of certain important factors. This paper recognizes that fact, and adduces figures only to take their place along with the other values to be considered.

The straw man having been set up and appropriately demolished, one may now turn to derive and advance a set of figures for damage,--good round figures that are an approximation, and are only correct (but at least correct) as to the placing of the thousand comma. Although there are many possible methods of derivation, depending on local conditions and on the basic data available, the underlying principles for calculation of gross estimates are the same in all cases.

The essentials required to obtain an approximate estimate are:

1. Maps showing the extent and intensity of the infestation. For convenience, intensity may be divided into three classes,- -heavy, medium and light. As

1 Contributian No. 2037, from the Division of Entomology, Science Service, Department of Agriculture, Ottawa. 
a result of the field activities of the various entomological laboratories, and of more comprehensive methods being developed in the Forest Insect Survey, we are now in a position to draw such maps. These are based on a large number of reports from independent sources, and may be considered of sufficient accuracy to give a fair picture.

2. Estimates of the volume of the various tree species over unit areas or districts. The forest services of the Dominion and of several provinces have made such forest inventories available in published form. Reference is made especially to the excellent compilation of Mulholland, "Forest Resources of British Columbia;" and to Morison's, "The Forests of New Brunswick." Similar works are published for Ontario and Manitoba. For other provinces, the data are either more generalized or else not so readily available.

3. Sample plots in the areas of infestation. Such plots, of an area of about $1 / 10$ of an acre, may be established without much cost or labour, in easily accessible localities. As they are revisited from year to year, the course of the infestation and its aftermath can be followed. Such plots have been established in most of the infestations now current, but the number of plots is not always sufficient to cover the various conditions of the infestation, and in some cases the data obtained could be put in more available form. Using these three classes of basic data, a gross estimate of mortality may be derived. The steps employed are as shown in Table I. Be it noted at this point that the figures represent only actual mortality of trees; no attempt is made here to estimate loss of increment on trees still living. Knowing the area of the infestation and the stand per acre on that area, the total volume of the tree species in question on the infested area may be calculated. To this the percentage mortality figure, obtained from sample plots, is applied; and thus a gross estimate of mortality is obtained.

\section{TABLE I}

Derivation of Figure for Damage by Spruce Budworm to Balsam Fir in Algoma, 1935 to 1939

Area of Heavy Infestation $=3,000$ sq. miles or 1,920,000 acres (data taken from Infestation Map)

Average Volume of Balsam over infested area $=0.50$ cords per acre (data taken from Sharpe and Brodie: "Forest Resources of Ontario").

$\therefore$ Balsam present on Heavily-Infested Area $=960,000$ cords.

Mortality of Balsam in heavy infestation $=95 \%$ (data obtained by establishing Sample Plots in the area)

$\therefore$ Total Mortality $=95 \% \times 960,000=910,000$ cords.

Damage to timber by forest insects is a relatively slow process, and accumulates from year to year until it results in actual mortality. In some cases, as the Spruce Budworm and Jack Pine Budworm, this mortality first appears in the second year of heavy attack; for the European Spruce Sawfly the process is 
slower; while in, infestations of Bronze Birch Borer, Beech Scale and Balsam Woolly Aphid, it may take a decade before mortality becomes apparent. Thus, in any estimate of annual damage, it is necessary first to obtain the figure for mortality since the infestation began, and then to derive the current annual figure either by subtraction of the previous year's figure, or, if this is not available, by arbitrary estimate.

Then again it is often difficult to separate the work of the true primary species (generally a defoliator) and secondary insects (generally attacking the stem). In most cases it is just to ascribe the damage almost in toto to the primary insect. In others, the secondary species is brought into the picture, especially when it is capable of continuing the infestation on its own.

Figures may now be advanced for the situation in 1939. The mortality since the inception of each infestation is calculated first, and then the current mortality for the year 1939 is derived. Set forth below are figures for a gross estimate of damage by eleven of the most important forest insect species of the past decade. The manner of their derivation, the location of the infestation, and the source material employed, are indicated in each case. Finally, the complete set of figures is summarized in Table II.

\section{European Spruce Sawfly}

Gaspé ( $50-60 \%$ of 14 to 20 million cords)

Matapedia Valley

$$
\begin{array}{rc}
8,000,000 & \text { cords* } \\
350,000 & \cdots \\
50,000 & \cdots \\
100,000 & \cdots
\end{array}
$$

New Brunswick (2\% of 5 million cords)

Sources: Balch, Pulp and Paper Magazine of Canada, Pebruary, 1940.

Gobeil, Bulletin 2, Service d'Entomologie, Quebec.

Morison, Bulletin 91, Dominion Forest Service, Ottawa.

\section{Spruce Budworm}

Algoma (95\% of 960,000 cords: heavy infest'n) 910,000 cords Balsam

( $5 \%$ of 1.5 million: medium infestation) 75,000 cords Balsam

( $5 \%$ of 2.3 million cords)

Barkerville, B.C.

115,000 cords Spruce

16,000 cords Alpine Fir

Sources: Atwood, Qualitative and rough quantitative reports.

Sharpe and Brodie, "Forest Resources of Ontario," Toronto, 1931.

Hopping, Qualitative reports.

Mulholland, "Forest Resources of British Columbia," Victoria, 1937.

\section{Jack Pine Budworm}

Kenora (15\% of 10 million cords)

Rainy River and Thunder Bay

Southern Manitoba (15\% of 743,000 cords)

$$
\begin{array}{r}
1,500,000 \text { cords } \\
600,000 \text { cords } \\
110,000 \text { cords }
\end{array}
$$

-Includes 4,500,000 cords killed by Eastern Spruce Bark Beetle. 
Sources: Richmond, "Deterioration of Jack Pine in Northwestern Ontario resulting from defoliation by the Jack Pine Budworm," Unpublished report, 1939.

Sharpe and Brodie, Loc. cit.

Harrison, Bulletin 85, Dominion Forest Service, Ottawa.

\section{Bronze Birch Borer}

New Brunswick and Nova Scotia (55\% of 19 million)

Manitoba and Saskatchewan (10\% of 1.5 million)

$10,500,000$ cords

Ontario and Quebec

150,000 cords

200,000 cords

Sources: Prebble and Balch, Forestry Chronicle Vol. 16: 179.201 Morison, Loc. cit.

Harrison, Bulletin 88, Dominion Forest Service, Ottawa.

\section{Hemlock Looper}

Muskoka (25\% of 60,000 cords)

15,000 cords

For infestation in British Columbia, information insufficient.

Sources: No quantitative estimates available.

\section{Beech Scale}

Nova Scotia ( $70 \%$ of 5.7 million cords)

Southern New Brunswick (20\% of 558,000 cords)

Central New Brunswick (3\% of 590,000 cords)

Cape Breton Island and Prince Edward Island

$\begin{array}{rc}4,000,000 & \text { cords } \\ 110,000 & \text { ". } \\ 18,000 & \text { “. } \\ 15,000 & \end{array}$

Sources: Balch, Personal communication; approx. percentage mortality.

Morison, Loc. cit.

Fernow, "Forest Conditions of Nova Scotia," Commission of

Balsam Woolly Aphid

Southern New Brunswick

Cape Breton Island

Remainder of Nova Scotia (10\% of 3 million)

113,000 cords

210,000

300,000

Sources: Balch, Unpublished reports and communications.

Fernow, Loc. cit. and Morison, Loc. cit.

\section{Larch Sawfly}

Kapuskasing $\cdot$ Abitibi region

Remainder of Quebec

Southern New Brunswick

Algoma and Nipissing

1,500 cords

(Mortality at 2\%; tamarack at 4 cords per sq. mile, as in N.B.)

Sources: Atwood, Personal communications.

Miscellaneous Forest Insect Survey data.

Morison, Loc. cit. 


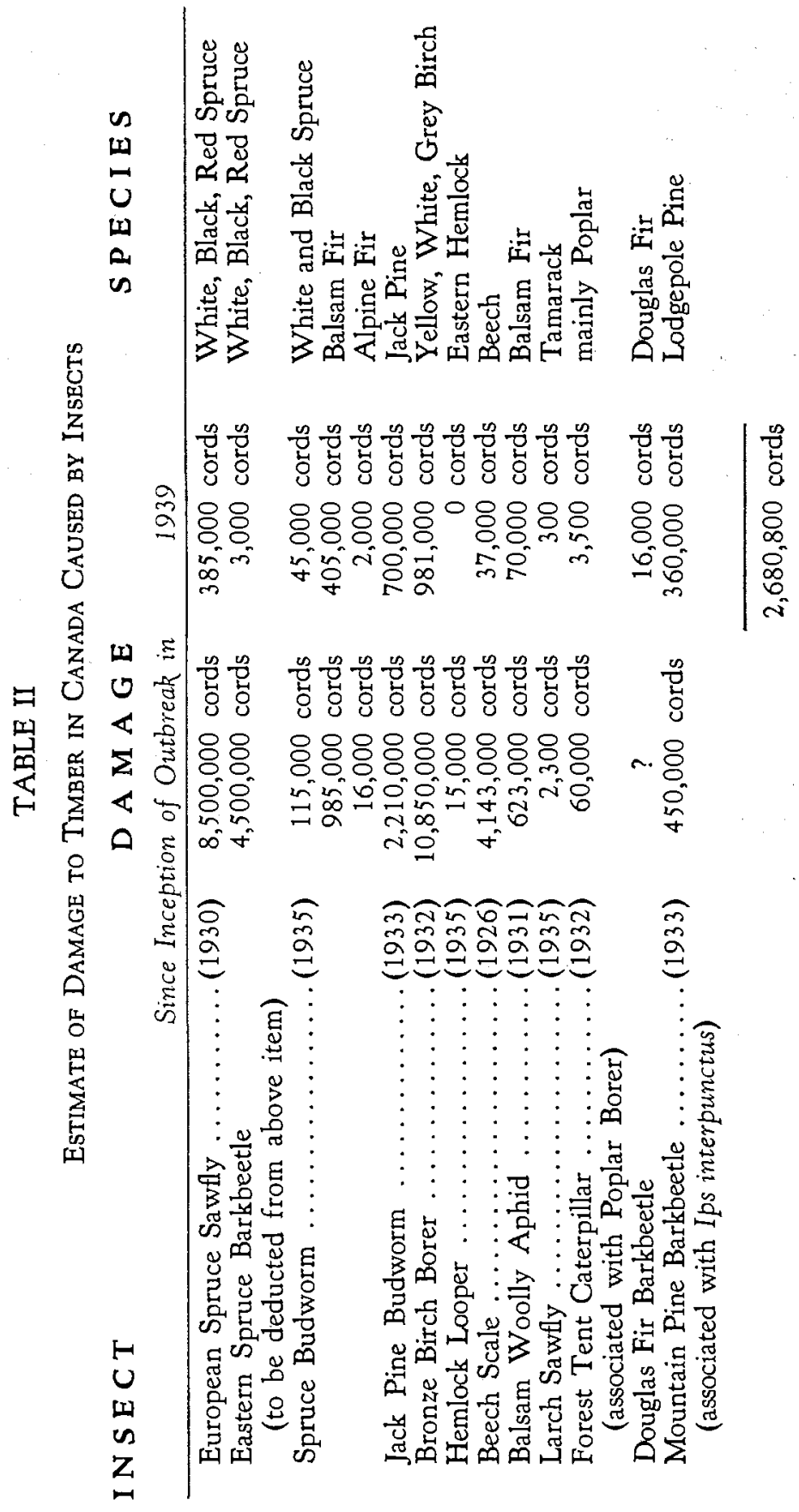




\section{Forest Tent Caterpillar}

$\begin{array}{llr}\text { Nipissing area } & \text { (5\% of } 150,000 \text { cords) } & 7,500 \text { cords } \\ \text { Port Arthur area } & \text { (5\% of } 480,000 \text { cords) } & 24,000 \\ \text { Northern Kenora } & \text { (5\% of } 450,000 \text { cords) } & 22,500 \\ \text { Northern Saskatchewan } & \text { " } \\ \text { N } & 6,000\end{array}$

Sources: Miscellaneous Forest Insect Survey data. Harrison, Bulletin 88, Dominion Forest Service, Ottawa.

\section{Mountain Pine Barkbeetle}

Kootenay Park $(45,000$ acres at 10 cords per acre) 450,000 cords Source: Hopping, Sample plot figures and infestation map (unpublished).

The salient features of this gross estimate of annual damage may be noted from an examination of Table II. It is interesting that the greatest destruction to commercial volume is caused, according to these figures, by the Bronze Birch Borer. Another slow-acting pest of hardwoods, the Beech Scale, is seen to be surprisingly important in point of volume of wood destroyed. Whereas the European Spruce Sawfly is undoubtedly an important forest insect, especially in view of the species of tree attacked, in point of annual damage it is now being easily outstripped by the Spruce Budworm. The exceedingly low mortality figure for tamarack due to Larch Sawfly may well be noted.

The above estimate, for eleven only of the more destructive species, totals $2,680,800$ cords, or roughly $300,000,000$ cubic feet. In addition, there are some insect species, attacking mainly young trees in plantations or elsewhere, e.g., White Pine Weevil and European Pine Shoot Moth, for which no estimate can be attempted. There are others which are of local occurrence and which cause only light or unnoticed infestations. Taking into account these other species, and adding to the mortality estimate a figure for loss of increment, it is possible that the annual damage due to forest insects may be approximately double the above figure. This may be compared with the annual cut of 2,570,000,000 cubic feet and an annual fire loss of 570,000,000 cubic feet (Canada Year Book, 1939), and would approach the figure of 700,000 , 000 cubic feet for forest insect loss there adduced by the late Roland Craig. 